\title{
Teaching Engaged Ethnography and Socio-cultural Change: Participating in an Urban Movement
}

\author{
Eleftheria Deltsou, Assistant Professor of Anthropology, \\ University of Thessaly
}

\begin{abstract}
How can ethnographic research be taught? What kinds of ethnographic environments are involved in the study of contemporary socio-cultural issues? How/where can socio-cultural change be spotted? Where do ethnographic reflexivity and engaged ethnography stand with regard to comprehending and furthering sociocultural change? Can/should ethnographic work fully conflate with critical activism? Can the teaching of engaged ethnographic research instigate critical awareness of the researcher's positionality(ies)? Considerations of the above questions will be endeavored via the participation of the author in an urban movement in Thessaloniki, Greece. Her double engagement as resident and academic teacher will expose the interrelatedness of these issues and the methodological, epistemological, and political implications that engaged ethnography raises.
\end{abstract}

Keywords: pedagogy of ethnography, participant observation, Facebook ethnography, critical social theory, theory/action relationship.

\section{Introduction}

As an anthropology professor for more than a couple of decades, I have come to realize that many students (but not only them) still tend to think of several aspects of social life in some way essentialist, ontological terms. Quite often, when faced with bigger pictures and larger questions than that of the everyday, the questions that they set forth still concern the definition of culture/society and the functionalist assumption of what sociocultural phenomena do. These types of questions evoke the characteristics of essentialism. On the one hand they suppress the temporality of socio-cultural formations, and on the other they attribute an unchanging ontology to historically contingent products of agency (Herzfeld, 2002), negating the processes of social and cultural change.

Of course, anthropology has long abandoned essentialist questions (e.g., Barth, 1967), having acknowledged that all "cultures", "societies" are historical, without delimited boundaries and in the process of continuous transformation. Whatever other concepts have been suggested in replacement of "culture" and "society", those also try to avoid the pitfalls of essentializing and substantiating the studied people and human and non-human lives as stable and circumscribed entities. Yet, the issue of change itself may too become essentialist if approached in the sense of a definition, and not in terms of how it occurs as a continuous condition of transformation. It is thus central to guide students away from ontological perceptions of the social/cultural toward awareness of being incessantly dynamic, and in a continuous flow (see Ervin, 2014). Students should perceive this change as something that occurs continuously, frequently in less- or non-obvious ways, but also in dramatic ways, opening perhaps new possibilities and subjectivities, but also realizing social conditions in so far unimagined everyday worlds (Greenhouse et al., 2002).

This anthropological awareness comes from ethnography. This irreplaceable methodology locates and attributes significance to any and all minute, more and less discernible aspects of human behavior. However, how can ethnographic research be taught as methodology, when its focus is on socio-cultural change? 


\section{The Pedagogy of Ethnography}

It has been a while since the ethnographic field was associated exclusively with participating and observing a group of people at a certain place. Meanwhile ethnography has been dissociated from ideas of locality (see Gupta \& Ferguson, 1997a \& 1997b; Wittel, 2000) and enriched with many different forms and layers. The following forms of ethnography are just indicative: multi-sited ethnography, where the ethnographer does research in different locations in the context of a single study in order to study dispersed phenomena (Marcus, 1995); sensory ethnography that takes account of sensory experiences, perceptions and categories in everyday life (Pink, 2009); digital and social media ethnographies, which involve ethnographic participatory research in digital environments (but perhaps also at the same time in analog environments) (Postill \& Pink, 2012); paraethnography, which attempts to pursue anthropological ethnography within contexts greatly managed by scientific knowledge and/or a technocratic ethos, but with critical sensibilities (Holmes \& Marcus, 2008); the essentially pedagogical para-sites or collaborative seminar-room conversations, which constitute an overlapping academic/fieldwork space in contemporary ethnographic projects set by scholars and epistemic partners alikei; ethnocharettes, which reconsider the textual form of ethnographies via design studio principlesii; experimental spaces, which involve experimentation in research, as well as in ethnographic pedagogy $y^{\text {iiii }}$. In the context of the many different kinds of ethnographic fields, can there be a general perception of ethnography? Are we able to say whether/how ethnography can be taught and, accordingly, what can be its pedagogy regarding social/cultural change?

While there have been publications with guidelines on how to do ethnographic participant observation (see, amongst others, Davies, 2007; DeWalt \& DeWalt, 2010; Spradley, 1980), little has been said on the pedagogy of

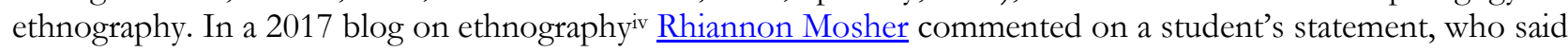
that ethnographies "... give students the sense that they "understand" phenomena they've never had personal experience with". For Mosher, university instructors who teach ethnography should read this complaint as a teachable moment of a failure that raises the question how to teach ethnography better. Mosher mentions some posts and articles that may help instructors in the classroom to encourage critical engagement with ethnographic texts and suggests how to teach ethnography as a method. However, there is only one publication that refers specifically to this issue. This is McGranahan's "What is Ethnography? Teaching Ethnographic Sensibilities without Fieldwork" (2014), whose views on the issue I will present here. McGranahan considers that since ethnography has something unique as a way of research, its pedagogy (i.e.to get students to think and feel ethnographically) requires first good comprehension of ethnography and ethnographic research (McGranahan, 2014, p. 24-25). This is a knowledge primarily acquired by reading anthropological history, theory, and good ethnographies. Similarly to Taussig's (2010) view that the two most important aspects of ethnography -how to do fieldwork and how to write- are secret-society-type shenanigans, McGranahan (2014) warned against obscuring and mystifying the workings and preparations of ethnographic research. At the same time she suggested that ethnographic research per se cannot be really taught but is learned by doing. Thus its pedagogy relies on the acquisition of disciplinary knowledge, methodological strategies, and theoretical frameworks. It involves the development of ethnographic sensibility as an intellectual (and moral) positionality and a bodily process in space and time (Ortner in McGranahan, 2014, p. 27).

To approach the question of ethnographic pedagogy, one needs to keep in mind the changes that have taken and are taking place within and under the umbrella of the ethnographic field and their implications on participant observation, observant participation, etc. For McGranahan, the thickness of ethnographic research comes from participant-observation. This involves the "being there" with all its disruptions and unsettling moments; the bodily and epistemological uncertainty as a critical part of ethnographic research; "listening for hesitationlistening for that which persistently disrupts the security of what is known for sure" (Stevenson in McGranahan 2014, p. 27). McGranahan did not limit this thickness to Malinowskian or Geertzian style ethnography, disregarding later textualist scholarship as a cultural critique style that "put[s] things together" (Borneman \& Hammoudi in McGranahan, 2014, p. 30). Nonetheless she wondered whether the subsequent development of unconventional versions of the ethnographic field without conventional fieldwork ethnography and the ethnographic do not just become some other type of qualitative research (2014: 29). This leads one to ask - why call it ethnography after all?

Anthropological ethnographic training concerns both the execution of the research and the understanding of the ethnographic, as well as the ability to see the ethnographic in unexpected places (e.g. in archives) (McGranahan 2014, p. 31). Hence, the pedagogy of ethnographic training is experience. It involves getting students to reflect on new and seemingly "foreign" topics from within their own ways; to understand how this is felt and lived; to 
move between subjectivities; to try to get to the culturally obvious through various ways; to pay attention to ethnographic sensibilities (McGranahan, 2014, p. 33). Pedagogically, this is a new old-fashioned anthropology that involves being there and knowing people. It is long-term ethnographic research with deep empirical knowledge, and ethnographic intimacy that produces embodied and experiential knowledge. It includes various fieldwork encounters in many different settings and on many different topics. However, as McGranahan points out (2014, pp. 33-34), teaching students ethnographic sensibility is important for its transformative possibilities: ethnographic knowledge is produced out of real-life encounters between people; ethnographic research requires care and commitment, humility and cooperation, vulnerability and trust; it is one of the most affecting ways of knowing another and, of course, knowing the self.

The pedagogy of ethnography, however, does not end there. All these aspects of ethnographic fieldwork go together with a sense of vagueness and the lack of certainties that one experiences in the course of research. Can the handling of such feelings be taught? How can students be convinced about doing ethnography when one continuously feels as if standing on unstable grounds? At the same time, leaving aside opposing or congruent arguments regarding the different types of field sites, should students also be trained as bloggers, Twitter users, journalists, YouTubers, social media experts to be able to conduct research on the new fieldwork sites that have emerged? Should the ethnographic findings be brought to the people studied in an effort to reach a common viewpoint that would be as much theirs as the anthropologists? It seems to me that there cannot be absolute answers to these questions. Just as ethnography is a permanently incomplete task, so is its pedagogy. However, what can be said is that classic ethnographic participant observation, particularly in relation to the increasingly dominant short-stay ethnographic research, establishes the merits of ethnographic research as an ascomprehensive-as-possible way of knowing. In Fassin's words, it is a space "where true life and real lives meet" (Fassin in Joshi, 2014).

\section{The Pedagogy of Change}

The next issue is whether and how the pedagogy of ethnographic research involving socio-cultural change can be accomplished. To approach this question I will rely on my personal experience both as an anthropology teacher and as a researcher. I will try to see the relevance of ethnographic and theoretical perspectives in comprehending what socio-cultural change is and where it can be "located". I cannot really testify if it is a general trait amongst all current anthropology (undergraduate and graduate) students. However I have often seen students fear "classic" ethnographic fieldwork, while at the same time consider social media as "natural", paper-related, ethnographic research fields. I do not mean to imply here that this generation of "digital natives" fear face-toface individual encounters and thus prefer digital worlds. At the same time, I should also admit and take into consideration my personal discomfort not with social media research, but with the prevalence of social media in general. This restrained me from encouraging students to do research on what they seem to know best - social media. On a personal level, I kept away from social media as a political choice to stay away from a continuous buzz of more or less relevant information and from specific types of digital public involvement and appearance. My attitude changed when I decided to expand my research on urban activism in my neighborhood in Thessaloniki, Greece. During this research a number of challenges emerged concerning the ethnographic method within this particular urban setting. The locality of the group was also globally constructed, and amongst other dimensions the field also involved a facebook $(\mathrm{Fb})$ web environment.

On the street where I live with my family, some people who reside here, work here, or even simply like the ways of this 'neighborhood', have set up a group that initially organized one neighborhood dinner on the street. The increasing success of the event during the next 4 years led the members to undertake new projects that are somehow more "involved" in public urban life. In the beginning I attended the dinners as a resident. However, when they organized a public consultation about the construction of a pocket park on a small abandoned piece of public land, I decided to join in and do at the same time ethnographic research. At the time, the group also expressed the plan to set up a "memory bank" of the neighborhood. This is a project that is currently running. I considered those activities great for me not only to study but also to join, as they were also of direct importance to my life and I wanted to be a part of this change. Thus, during one of the open meetings held by the group, I presented myself as a resident of the neighborhood and an anthropologist interested in urban activism. I joined in, adding that I would like to contribute in all possible ways. The immediate question I was asked was if I "had Fb", explaining that to be a member of the group I NEEDED to "have Fb." I thus overcame my previous objections, created my Fb profile, and not only became friends but joined the members of the group. I started an ethnographic project on an urban activist group, whose intervention in city life occurs as much through physical 
presence as through digital participation both as means of inside communication, but also as means of extroversion.

A number of questions emerged with regards to my new field. In what ways is participant observation feasible in a group that is at the same time locally, globally, and medially constructed? Does the group's Facebook field exhibit the same field relations found via classic participant observation? What does the ethnographic research of face-to-face and social media socialities show about the 'ethnographic place'? Through what forms of representation does the group construct itself (imagination and other mediated representations like film, documentary, artistic installation, biography, performance etc.), multiplying the mirrors of its representations? Is it possible to be engaged while doing ethnography in such a group? What difference does it make when one is also engaged in whatever this familiar neighborhood context, 'anthropology at home', may be? It pretty soon became obvious that the polymedia (i.e. local, global, medial) the group used as a communicative environment (Madianou \& Miller, 2013) could not be distinguished or hierarchized in terms of different channels and forms of communication for member interaction and action. As sharing experiences within this neighborhood activist group take place both online and offline, the ethnographic site is multiply constructed and it encompasses different ethnographic perspectives on media routines, mobilities and socialities (Pink, 2009). Thus, a field involving social media ethnography constructs the 'ethnographic place' as collaborative, participatory, open, and public (Pink, 2009; Postill \& Pink, 2012).

\section{Spotting Socio-Cultural Change.}

How can students learn to spot processes of socio-cultural change in multiply constructed ethnographic sites, and in general? While an overall answer cannot be given to this question, in the particular case of an activist group I believe that theoretical perspectives allow us to see new forms of cultural protest and confrontation as constitutive agencies of change (see Gibb, 2001). It is in alternative, more or less subversive, counterpublics where change not only takes place, but is planned to occur through actions that express disagreements and oppose public policies in the urban space. This creates the alternative practices in/for the public space (Deltsou \& Tsibiridou, 2018).

An ethnographic research on the aesthetic and cultural "alterpolitics" (Ciavolella \& Boni, 2015) that the group en-acts, helps the ethnographer perceive the group not as a given entity, but as a condition of continuous fluidity that is related to the kind of disruption of the existing political community. Such groups constitute 'schools of citizenship' that construct 'public socialities' (Avdela, 2015) and incorporate both the goal and the potential of socio-cultural change. Drawing on the trope 'the right to the city' (see Lefebvre, 1968; Harvey, 2008), such actions emerge as "forms of hope" for the construction of a different civility. They are a conciliation of multiple pasts and "co-futures", even though they are always re-constituted in the present (Nugent, 2012, p. 281). The acting agents, each one of them possibly in different ways, situate themselves in terms of a discrete temporality. It is a sense of rupture with the given, the "what is". It realizes itself as a sense of the new and unprecedented. It is a rupture with the past, both temporal and moral-ethical (Nugent, 2012: 281).

Such actions toward the near future give an understanding of change that is located in forms of "Otherwise" (Povinelli, 2014). These are acts of political becoming that pursue instrumentalist or expedient goals and articulate matters of common concern (Rethmann, 2013, p. 236). From Povinelli's (2014) perspective, within the given order of existents-as-arrangement, possible derangements and rearrangements are also installed. The "Otherwise" are immanent derangements and rearrangements, located within forms of life at odds with dominant and dominating modes of being (Povinelli, 2011). The temporal horizon is the future. It is a yetundefined imagined future that offers hope, promise, and possibility. It is to be glimpsed in groups and processes that are located beyond what is in the materialization of new social relations and ethical practices, through which new forms of personhood and politics emerge (Nugent, 2012, p. 282).

\section{Ethnographic Reflexivity, Engaged Ethnography and Socio-Cultural Change}

How do ethnographic reflexivity and engaged ethnography stand with regard to comprehending and furthering socio-cultural change? The relationship between ethnographers and the people studied is neither clear nor granted. At the same time, the goal of critical ethnography is to change people's conditions of existence in emancipatory and empowering ways. This uneasy relationship between emancipatory social theory and ethnographic research has led post-critical ethnography to problematize the theoretical assumptions anthropologists bring to the field (Hytten, 2004). In this direction the following questions are open for 
discussion. Can/should ethnographic work fully conflate with critical activism? Can the teaching of engaged ethnographic research instigate critical awareness of the researcher's positionality(ies)?

Guajardo et. al., (2008, p. 7-8) bring together issues that concern epistemology, education, activist ethnography, and the pedagogy of hope. They set as their task not just to construct a different theory of practice, but also to rupture the traditional paradigms and to use methods as an instrument for change. They argued that it is through research and inquiry that the paradigmatic membrane breaks and the tools or methods that have historically kept knowledge and power for the privileged get deconstructed. This is the occasion to begin rebuilding. In that direction they see that the decolonization of the research process disrupts the traditional paradigm. It acknowledges the strengths and the needs of the local community and makes space for new voices to arise. Thus it contributes to a new method for documentation and knowledge creation. They consider themselves as activist academics and community developers. They thus demarcate their activist research work away from money and trends toward a constant commitment to change views in people, families, and in institutions.

For Sieder (2013), engaged ethnography is just like any other good ethnography. It puts the actors and their understandings of the world at the center of analysis. Dissimilarly, it privileges the group's collective aims, objectives, dialogue, and the co-production of knowledge, combining careful, empirical participant-observation, critical social theory and other collaborative research methods and outputs (e.g., workshops, the production of videos and popular education materials). Engaged ethnography becomes part of a broader activist scholarship that seeks to disclose the workings of power, history, and transnational forces, as those affect indigenous people's lives and shape different forms of resistance and adaptation. Such research can ascertain alternative epistemologies or ways of being in the world by approaching them as situated ways of theorizing social reality, and can also support indigenous people's rights and interests (Sieder, 2013, pp. 223-224).

In comparison to such approaches of activist scholarship, I do not consider my research to be evidently "activist", or at least I am not absolutely certain about it yet. Being personally involved in the urban movement I mentioned, I definitely wish to contribute to 'validating alternative epistemologies or ways of being in the world, understanding these as situated ways of theorizing social reality' (Sieder, 2013, p. 224). Yet, I am not certain in what ways my situated anthropological knowledge and academic position should contribute in defending collective rights and interests. I actually ponder over whether my involvement should bring into the group the authority of social theory as a way of forming and transforming people's choices and actions. While I am not the only member of the group that carries the symbolic value of social theory as "superior academic knowledge", in this relationship between theory and action, for me, the prevalence of theory is not indisputable.

\section{By way of Closure}

My multifarious engagement in the ethnographic research (as a resident of the neighborhood, member of the activist group, ethnographer, and academic teacher) exposes the interrelatedness amongst the methodological, epistemological, and political dimensions. I hope that my experience serves to demonstrate the implications raised by engaged ethnography. I do not have an overall answer to the questions of the pedagogy of ethnography and change. However, I think that the main guideline is to expose students to the complexity of the relationships among theories, research questions, and methods of research, in order to lead them toward a critical reflection on all of them. Probably most importantly is to teach them to resist to ethnographic ontologies as ontologies per se.

\section{References}

Avdela, E. (2015). Introduction: Collective Action and the Production of Public Sociality in $20^{\text {th }}$ century Greece. In E. Avdela, Ch. Exertzoglou, Ch. Lirintzis (eds), Public Socialities in 20 th Century Greece, University of Crete Press, pp. 11-38. (in Greek)

Barth, F. (1967). On the Study of Social Change. American Anthropologist, 69, 6, 661-669.

Ciavolella, R., \& Boni, S. (2015). Aspiring to alterpolitics: Anthropology, radical theory, and social movements. Focaal-Journal of Global and Historical Anthropology, 72, 3-8.

Davies, C.A. (2007). Reflexive Ethnography: A Guide to Researching Selves and Others, Routledge 
Deltsou, E., \& Tsibiridou, F. (2017). Introduction: Urban Lives and Protests in Neoliberal Times: Art, Aesthetics and Solidarity as Possibilities. The Greek Review of Social Research, 149, 149, 3-16. Accessed at doi:http://dx.doi.org/10.12681/grst.15810

DeWalt K.M., \& DeWalt, B.R. (2010). Participant Observation: A Guide for Fieldworkers. AltaMira Press

Ervin, A.M. (2014). Cultural Transformations and Globalization, Routledge.

Gibb, R. (2001). Toward an anthropology of social movements. Journal des anthropologues, 85-86, 233-253.

Greenhouse, C.G., Mertz, E., \& Warren K.B. (eds) (2002). Ethnography In Unstable Places: Everyday Lives In Contexts Of Dramatic Political Change. Duke University Press.

Gupta, A., \& Ferguson, J. (eds) (1997a). Culture, Power, Place: Explorations in Critical Anthropology. Durham: Duke University Press.

---- (1997b). Anthropological Locations: Boundaries And Grounds Of A Field Science. University of California Press.

Harvey, D. (2008). The right to the city. New Left Review, 53, 23-40

Herzfeld, M. (2002). Essentialism', in A. Barnard and J. Spencer (eds). The Encyclopedia of Social and Cultural Anthropology, Routledge, pp. 188-190.

Holbraad, M., Pedersen, M. A., \& Viveiros de Castro, E. (2014). The Politics of Ontology: Anthropological Positions. Theorizing the Contemporary, Cultural Anthropology website, January 13, 2014.

https://culanth.org/fieldsights/462-the-politics-of-ontology-anthropological-positions.

Holmes, D. R., \& Marcus, G. E. (2008). 'Para-Ethnography', in L.M. Given, The Sage Encyclopedia of Qualitative Research Methods, Sage, accessed at http://dx.doi.org/10.4135/9781412963909.n307

Hytten, K. (2004). Postcritical Ethnography: Research as a Pedagogical Encounter. In G. B. Noblit, S. Y. Flores and E. G. Murillo Jr. (eds), Postcritical Ethnography: Reinscribing Critique (Understanding Education and Policy), Hampton Press, pp. 95-105

Lefebvre, H. (1968). Le Droit à la ville, Paris, Anthropos (2nd ed.). Paris, Ed. du Seuil.

Marcus, G. E. (1995). Ethnography in/of the World System: The Emergence of Multi-Sited Ethnography. Annual Review of Antbropology, 24, 1, 95-117

McGranahan, C. (2014). What is Ethnography? Teaching Ethnographic Sensibilities without Fieldwork. Teacbing Anthropology, 4, 23-36.

Nugent, D. (2012). Commentary: Democracy, Temporalities Of Capitalism, And Dilemmas Of Inclusion In Occupy Movements. American Ethnologist, 39, 2, 280-283.

Pink, S. (2009). Doing Sensory Ethnography, London, Sage.

Postill, J., \& Pink, S. (2012). Social Media Ethnography: The Digital Researcher in a Messy Web. Media International Australia Incorporating Culture and Policy: quarterly journal of media research and resources, 145, 123-134.

Povinelli, E.A. (2011). Routes/Worlds,' e-flux, September 27, http://www.e-flux.com/journal/routesworlds/ ---- (2014). Geontologies of the otherwise, Theorizing the contemporary. Cultural Anthropology website (published online January 13) https://culanth.org/fieldsights/465-geontologies-of-the-otherwise

Rethmann, P. (2013). Imagining political possibility in an age of late liberalism and cynical reason. Reviens in Anthropology, 42, 227-242.

Sieder, R. (2013). Subaltern Cosmopolitan Legalities and the Challenges of Engaged Ethnography. Universitas Humanistica, 75, 219-247. 
Spradley, J. (1980). Participant Observation. Holt, Rinehart and Winston.

Taussig, M. (2010). The Corn-Wolf: Writing Apotropaic Texts. Critical Inquiry 37, 1, 26-33

Wittel, A. (2000). Ethnography on the Move: From Field to Net to Internet. Forum Qualitative Sozialforschung /

Forum: Qualitative Social Research, 1, 1, Art. 21, accessed at http://nbn-resolving.de/urn:nbn:de:0114-fqs0001213.

\section{Notes:}

${ }^{i}$ https://www.ethnography.uci.edu/tactics/para site.php

ii $\underline{\text { https://www.ethnography.uci.edu/tactics/ethnocharrette.php }}$

iii http://centerforethnography.org/content/uci-experimental-ethnography-working-group

iv $\underline{\text { http://anthrolens.blogspot.com/2017/01/teaching-ethnography.html }}$ 